\title{
Measuring severe adverse events and medication selection using a "PEER Report" for nonpsychotic patients: a retrospective chart review
}

This article was published in the following Dove Press journal:

Neuropsychiatric Disease and Treatment

22 June 2012

Number of times this article has been viewed

\section{Daniel A Hoffman' \\ Charles DeBattista ${ }^{2}$ \\ Robert J Valuck ${ }^{3}$ \\ Dan V losifescu ${ }^{4}$}

'Neuro-Therapy Clinic, Inc, Denver, CO, USA; ${ }^{2}$ Stanford University School of Medicine, Palo Alto, CA, USA; ${ }^{3}$ University of Colorado, Skaggs School of Pharmacy and Pharmaceutical Sciences, Aurora, CO, USA; ${ }^{4}$ Mood and Anxiety Disorders

Program, Mount Sinai School of Medicine, New York, NY, USA
Correspondence: Daniel A Hoffman 7800 East Orchard Road, Suite 340, Greenwood Village, CO 80I II, USA $\mathrm{Tel}+\mathrm{I} 303$ 74| 4800

Fax +I $30374 \mid 2244$

Email daniel@hoffmanemail.com
Abstract: We previously reported on an objective new tool that uses quantitative electroencephalography (QEEG) normative- and referenced-electroencephalography sampling databases (currently called Psychiatric EEG Evaluation Registry [PEER]), which may assist physicians in determining medication selection for optimal efficacy to overcome trial-and-error prescribing. The PEER test compares drug-free QEEG features for individual patients to a database of patients with similar EEG patterns and known outcomes after pharmacological interventions. Based on specific EEG data elements and historical outcomes, the PEER Report may also serve as a marker of future severe adverse events (eg, agitation, hostility, aggressiveness, suicidality, homicidality, mania, hypomania) with specific medications. We used a retrospective chart review to investigate the clinical utility of such a registry in a naturalistic environment.

Results: This chart review demonstrated significant improvement on the global assessment scales Clinical Global Impression - Improvement and Quality of Life Enjoyment and Satisfaction - Short Form as well as time to maximum medical improvement and decreased suicidality occurrences. The review also showed that $54.5 \%$ of previous medications causing a severe adverse event would have been raised as a caution had the PEER Report been available at the time the drug was prescribed. Finally, due to the significant amount of off-label prescribing of psychotropic medications, additional, objective, evidence-based data aided the prescriber toward better choices.

Conclusion: The PEER Report may be useful, particularly in treatment-resistant patients, in helping to guide medication selection. Based on the preliminary data obtained from this chart review, additional studies are warranted to establish the safety and efficacy of adding PEER data when making medication decisions.

Keywords: PEER, referenced-EEG, QEEG, adverse events, medication selection, off label

\section{Introduction}

A large body of the recent psychiatric literature is questioning the empirical value of current prescribing habits as well as the psychiatrists' choice of medication selection as increasing amounts of polypharmacy and risk of medications creep into patients' regimes. ${ }^{1-12}$ Without better evidence-based research, often medication choices are made by trial and error, leading to significant delays to effective treatment.

There is little empirical evidence supporting the benefits of polypharmacy, and continuing a trial-and-error approach to the implementation of psychotropic medications. This is discussed in a recently published paper ${ }^{1}$ in which polypharmacy is compared to washing patients out of their current medication as a possible next step in medication management. In the newly reported Combining Medication to Enhance 
Depression Outcomes study, ${ }^{13}$ a National Institutes of Health (NIH)-funded research to determine whether starting several antidepressants at the same time would be associated with increased efficacy, no significant difference between the response or remission rates were observed. However, there were substantial side effects when combining medications. This large, well-designed study supports the contention that psychiatry is still in need of evidence-based tools to orient psychotropic treatment selection. This same conclusion was highlighted by recent programmatic documents of the National Institute of Mental Health (NIMH), which highlighted the need for objective evidence-based neuroscience ${ }^{14-17}$ instruments in addition to diagnoses based on symptom clusters in selecting the most effective treatments.

Additionally, reports from the large NIH-funded Sequence Treatment Alternatives to Relieve Depression (STAR*D) study, ${ }^{18}$ as well as other publications, ${ }^{19,20}$ have revealed the lack of biomarkers and the limitations of relying on symptombased prescribing followed by "watchful waiting" in state-ofthe-art psychiatric treatment. This has not resulted in reliable predictors of response to pharmacotherapy.

Quantitative electroencephalography (QEEG) - which involves computerized spectral analysis of electroencephalography (EEG) signals provides information that cannot be extracted through visual inspection of EEG alone - and has been previously used to predict the outcome of antidepressant treatment. Some studies suggest that baseline QEEG parameters may also serve to predict the total burden of treatment-emergent side effects or more specifically to predict treatment-emergent suicidal ideation. ${ }^{21,22}$

There is ample previous evidence for the QEEG-based treatment outcomes in the literature. Suffin and Emory, ${ }^{23}$ through referenced-EEG (now called Psychiatric EEG Evaluation Registry or PEER Report), initially examined attentional and affective disorders and their successful association with pharmacotherapeutic outcomes. Other smaller preliminary studies have suggested a potential role in using this information for medication selection for depression, ${ }^{24-26}$ eating disorders, ${ }^{27}$ and substance abuse ${ }^{25}$ with similar promising results. Another pilot study ${ }^{28}$ was conducted to compare this same methodology with the Texas Medication Algorithm Project (TMAP) used for patients with treatment-resistant depression. The data in that study resulted in statistically greater change from baseline outcome scores than those treated with TMAP-guided therapy.

In a larger, multicenter, randomized trial, DeBattista ${ }^{29}$ compared the referenced-EEG database treatment group (experimental) with an optimized treatment based on the
STAR*D study guidelines (control) in patients with treatmentrefractory major depressive disorder. ${ }^{18}$ The experimental group's selection led to statistically better outcomes compared with the control group. A recent retrospective chart review in the treatment of depression in eating disorders ${ }^{30}$ reported on 22 patients with a 2-year history prior to using the PEER Report to guide treatment and followed them for 2-5 years. Patients demonstrated significant decrease in depressive symptoms Hamilton Depression Rating Scale, severity of illness Clinical Global Impression - Severity (CGI-S), and overall Clinical Global Impression - Improvement (CGI-I).

The PEER Report information utilizing the referencedEEG database can assist clinicians treating nonpsychotic psychiatric patients with objective choices that offer (1) caution against medications potentially associated with adverse events for a given patient, while at the same time (2) giving evidence-based knowledge from other patients with similar brainwave patterns associated with positive responses to specific medications in the growing database. The PEER Report is based on specific EEG patterns before the patient begins treatment. The methodology for determining the medication ratings in the database has been previously published..$^{30}$

\section{Objective}

An uncontrolled retrospective chart review of clinical cases having received a QEEG utilizing the referenced-EEG database (now called PEER Report) was performed. The objective was to determine if PEER information would improve overall global ratings and quality of life in nonpsychotic patients in a typical psychiatric outpatient clinical setting. In addition, we hypothesized that the report might help caution the prescriber about the potential of severe adverse events and reduce the number of such negative outcomes.

\section{Methods}

\section{Subjects}

We reviewed the charts of 435 patients who elected to undergo QEEG assessment between 2003 through mid-2011 in an outpatient psychiatric clinic with three prescribers. Two were psychiatrists and one was a psychiatric clinical nurse specialist with prescriptive authority. Experience with the use of PEER varied. The patient population consisted of any nonpsychotic diagnosis typically seen in a private outpatient clinical setting that agreed to follow the medication plan suggested by the referencedEEG database and PEER Report, along with any comorbid 
conditions. The option for using the report was given to patients who could safely washout of medication for at least 5 half-lives and desired to add evidenced-based data to their treatment decisions. Most of them were treatment-resistant (having failed at least two previous medication trials). The patients had to pay for the test, but a compassionate-use policy allowed for a sliding scale. All patients receiving an EEG had signed two different informed consents stating that their data could be used for purposes of research or publication in the future and that all Health Insurance Portability and Accountability Act standards and personal health information would not be included or divulged in any way. They were also given choices of other treatments or allowed to cease testing at any time without affecting their treatment options, as per standard informed consent language. Abstracted data from the patient's chart included primary and secondary diagnoses, age, history of failed medication trials, adverse events to prior medications, severe adverse events (eg, agitation, hostility, aggressiveness, suicidality, homicidality, mania, hypomania), severity of symptoms, and off-label use.

\section{Clinical severity of patients' conditions}

In our clinic (Neuro-Therapy Clinic, Inc, Denver, CO) depression and anxiety rating scales are administered as part of the initial assessment for each new patient, regardless of diagnosis. Two different depression scales were used because the clinic changed assessment tools within the time period of the review.

Including all anxiety and depression scores for the population (even on patients without an anxiety or depression diagnosis) skews the group depression/anxiety statistics toward being less severe since many of the patients did not have depressive or anxious symptoms, thus causing lower scores than might be anticipated. (Table 1). Postdepression/anxiety scores were not available because outcomes were measured by global scores, such as CGI-I and Quality of Life Enjoyment and SatisfactionShort Form (Q-LES-Q-SF), in agreement with the "diagnostic agnostic" fundamentals of the PEER data.

\section{Clinical measures}

Clinical chart data was analyzed from the point of medication implementation (guided by the PEER Report) to the point where the prescriber determined patients were at maximum medical improvement (MMI) - the term traditionally used, in medical disability, for example, to define the point at which they were thought to be stable and at which no further medication changes would alter their outcome. The
Table I Treatment outcomes

\begin{tabular}{|c|c|c|}
\hline & Before & After \\
\hline Beck's depression & $29.8(5-56)$ & N/A \\
\hline inventory $(\mathrm{N}=100)$ & SD: 12.1 & \\
\hline \multirow[t]{2}{*}{ IDS-SR $(N=102)$} & $34.6(4-66)$ & N/A \\
\hline & SD: 13.1 & \\
\hline Beck's anxiety inventory & $18(0-58)$ & N/A \\
\hline$(N=190)$ & SD: 12 & \\
\hline \multirow[t]{4}{*}{ Mean number of drugs } & $5.9(0-24)$ & $2.4(0-7)$ \\
\hline & SD: 4.6 & Change $=3.5$ \\
\hline & & SD: 1.2 \\
\hline & & $P<0.001$ \\
\hline \multirow[t]{3}{*}{ Time to $\mathrm{MMI}$} & N/A & 3.3 (I-25) visits; \\
\hline & & $13 \mid(12-1449)$ days \\
\hline & & SD: I 28.4 \\
\hline \multirow[t]{3}{*}{ CGI-I } & 4 (baseline) & 1.86 \\
\hline & & Change $=-53.6 \%$ \\
\hline & & $P<0.001$ \\
\hline \multirow[t]{3}{*}{ Q-LES-Q-SF } & $47.1(16-88)$ & $71.2(38-100)$ \\
\hline & & Change $=24.6$ \\
\hline & & $P<0.001$ \\
\hline Suicide-related & $68(26 \%)$ & 9 (4\%; mean 722 days f/u) \\
\hline occurrences & & $P<0.001$ \\
\hline
\end{tabular}

Abbreviations: CGI-I, Clinical Global Impression - Improvement; f/u, follow-up; IDS-SR, Inventory of Depression Symptomology - Self-Rated; MMI, maximum medical improvement; Q-LES-Q-SF, Quality of Life Enjoyment and Satisfaction - Short Form.

outpatient clinic included three individual prescribers who rated patients at each session according to the CGI-I rating scale $^{31,32}$ at all visits since January 2009. Patients also filled out Q-LES-Q-SF ratings. ${ }^{33}$

Data pertaining to all known prior medications, along with known severe side effects, were also collected. Raw data was recorded on spreadsheets, and changes in scores were calculated by subtracting baseline scores from the MMI scores. The CGI-I ${ }^{31}$ is a well-accepted seven-point Likert scale used regularly in both clinical practice and research. A score of 4 means "no change," compared to baseline. One means "very much improved," two is "much improved," and three is "improved." Similarly, scores of 5-7 represent worsening. A score of 2 or 1 (much or very much improved) is typically used as the definition of a good clinical response.

The Q-LES-Q-SF ${ }^{33}$ is a quality-of-life questionnaire assessing 14 areas of a patient's life circumstances. The raw score is then transformed to a standardized scale of 0-100. While the Q-LES-Q-SF has never been normed into typical bands of mild, moderate, or severe, psychiatric patients in treatment who are considered responders tend to score in the mid-60s or above. Schechter et al, among others, have written that psychiatric patients successfully treated for depression and anxiety score in the mid- to upper-60s, while patients with moderate symptoms or who function with only some difficulty tend to score $\sim 64 \% .^{34-38}$ 


\section{Data analysis}

Descriptive statistics (mean, range, standard deviations, percentage change) were used to characterize study subjects on demographic and clinical measures at baseline, including age, severity of illness, history of failed medication trials, and previous severe adverse events prior to medications prescribed after initiating the PEER Report.

For the primary study outcomes, we performed Student's $t$-tests to compare the mean number of medications used by subjects, their mean improvement as measured by the CGI-I, and their mean quality of life scores as measured by the Q-LES-Q-SF, before and after starting PEER guided treatment.

Due to the relative rarity of events related to suicidality and the difficulty in determining exact pre-period time windows for specification of incidence rates per unit of time, we report suicidal occurrences as counts (number of events observed) before and after subjects started PEER-guided treatment. No statistical analyses were applied to the counts of suicide-related occurrences that were observed in this study. Rates of severe adverse events before and after subjects started PEER-guided treatment and rates of pre-off-label medication use were also reported. No statistical analyses were applied to the adverse event rates or off-label use rates that were measured in this study. Where there were no statistical analyses applied, it was either due to the fact that some measures had uncertainty about equal measurement intervals or we erred on the side of caution by not making statistical comparisons of pre versus post data since the rates of some measurements were so low that we did not have much statistical power to make adequate comparisons.

Statistical analyses were performed using SAS version 10.0 (SAS Institute Inc, Cary, NC). All tests were two-sided, with an a priori alpha-level of 0.05 for all comparisons.

\section{Results}

Charts of 435 psychiatric patients who elected to undergo QEEG assessment between 2003 through mid-2011 were reviewed. A total of 178 patients were excluded from the analysis for the following reasons: lost to follow-up, 127; noncompliance, 29; insufficient data, 16; other, 6 .
There were an additional 27 patients who, after their PEER assessment, did not need medication for their treatment. Abstracted data from the patient's chart included primary and secondary diagnoses, age, history of failed medication trials, adverse events to prior medications, severe adverse events (as mentioned previously), severity of symptoms, and off-label use.

The 230 patients who received and followed PEER averaged 36.4 (7-67.1; standard deviation [SD] 13.9) years of age. The average number of previous medication treatment failures was 5.9, dropping to 2.4 after treatment guided by the PEER Report (Table 1). These included either medications prescribed at the same time or failed attempts in both pre- and post-PEER guidance. Other outcome measures are also seen in Table 1.

The percent of patients lost to follow-up was similar to different comparable control populations. These included other patients seen in the clinic that did not get a QEEG, and published studies utilizing the referenced-EEG database for depression efficacy ${ }^{29}$ in treatment-resistant patients, and a retrospective chart review in the eating-disorder population ${ }^{30}$ (Table 2). Also noted in Table 2 is the additional benefit for $10.5 \%$ of those patients who required no pharmacological treatment after washout.

The outcome measurements were of two varieties. The first were statistics relating to average number of drugs used and time to MMI (Table 1). The second measurements were clinical global scores that would not be dependent on any diagnostic category but addressed overall functioning. Table 1 consists of the CGI-I and the Q-LES-Q-SF. Eighty-seven percent of patients achieved significant improvement (CGI-I of 1 or 2), and this was achieved within four visits for $68.7 \%$ of patients.

Previous suicidality was determined by reviewing the chart for patients' suicidal thoughts, ideations, plans, or attempts discovered in the intake and past history. If the same or different patient had any of these identical symptoms after starting the PEER-guided treatment, it was recorded as an occurrence. For those patients the review charting was followed throughout their association with the clinic, which averaged 721.9 (54-3591) days (Table 1).

Table 2 Patients lost to follow-up

\begin{tabular}{|c|c|c|c|c|}
\hline & $\begin{array}{l}\text { This chart } \\
\text { review }\end{array}$ & $\begin{array}{l}\text { NTC (control group; } \\
\text { non-PEER) }\end{array}$ & $\begin{array}{l}\text { Depression efficacy } \\
\text { study using PEER }{ }^{29}\end{array}$ & $\begin{array}{l}\text { Eating-disorder } \\
\text { study using PEER }\end{array}$ \\
\hline Lost to follow-up & $41 \%$ & $41 \%$ & $28 \%$ & $33 \%$ \\
\hline $\begin{array}{l}\text { Patients needing no medication } \\
\text { after washout }\end{array}$ & $10.5 \%$ & $0 \%$ & N/A & N/A \\
\hline
\end{tabular}




\section{Severe adverse events}

This chart review revealed $7 \%$ serious adverse events from patients' prior medications. For comparison, $7 \%$ of subjects in STAR*D level 1 who experienced treatment-emergent suicidal ideation experienced a new onset of suicidal ideation. ${ }^{39}$ Also, between $11.1 \%$ and $34.8 \%$ of patients in the NIMH STAR*D study who discontinued treatment in the second treatment level described severe adverse events as the reason..$^{40}$

In the current version of the PEER Report, medication classes as well as specific medications are rated in three categories based on the historical use from other providers' data in the registry for success (similar to an antibiotic sensitivity report). The three categories are "S" (sensitive or $>85 \%$ chance of treatment success), "I" (intermediate or $35 \%-85 \%$ ), and " $R$ " (resistant or $<35 \%$ chance of success). Reviewing all past medications and patient reported responses, severe adverse events (eg, agitation, hostility, aggressiveness, suicidality, homicidality, mania, hypomania) were noted and compared with the rating score of their current PEER Report. Medications rated "R" on the PEER Report were associated with rates of severe adverse effects $55 \%$ of the time. $\mathrm{R}$ ratings of medications can be considered as a potential cautionary flag in that, had the information been available at the time of giving the medication, the adverse response may have been prevented. The same analysis was performed in the dataset of a previously published multicenter Depression Efficacy Study ${ }^{29}$ (DES) testing PEER efficacy in major depressive disorder. In that dataset, R-rated medications were associated with severe adverse effects $50 \%$ of the time. Table 3 shows both studies along with the rating on the drug causing the significant adverse side effect. One drug in the chart review had insufficient information in the database to be included. The pooled results were statistically significant assuming an equal distribution across $\mathrm{R} / \mathrm{I} / \mathrm{S}$ categories as the null hypothesis.

\section{Discussion}

The medications prescribed based on review of the QEEG data contained in the current version of the referenced-EEG

Table 3 Severe adverse events and PEER Report medication rating

\begin{tabular}{lllll}
\hline Study & $\begin{array}{l}\text { Resistant } \\
\text { N (\%) }\end{array}$ & $\begin{array}{l}\text { Intermediate } \\
\text { N (\%) }\end{array}$ & $\begin{array}{l}\text { Sensitive } \\
\text { N (\%) }\end{array}$ & P-value* \\
\hline Chart review & $18(55 \%)$ & $7(21 \%)$ & $7(21 \%)$ & 0.0228 \\
DES study ${ }^{29}$ & $4(50 \%)$ & $2(25 \%)$ & $2(25 \%)$ & 0.6064 \\
Pooled result & $22(55 \%)$ & $9(22.5 \%)$ & $9(22.5 \%)$ & 0.0146 \\
\hline
\end{tabular}

Note: $*$ Chi-square test (for I $\times 3$ contingency table, $\mathrm{df}=2$ ).

Abbreviation: $\mathrm{df}$, degrees of freedom. database and PEER Report were from four different classes, ie, anticonvulsants, antidepressants, stimulants (which included monoamine oxidase inhibitors due to their stimulating effect on the EEG and the way the database classifies them), and beta-blockers. Patients were treated with either monotherapy or combinations of medications guided by the four categories listed in the PEER Report. Clinical judgment always superseded data from the report as the PEER Report offers more data to incorporate into the clinical decisionmaking process and is not meant as a stand-alone cookbook for psychotropic medications.

Since not all medications are part of the current version of the database, substitutions were allowed in the following instances: duloxetine for venlafaxine; oxcarbazepine for carbamazepine; and lisdexamphetamine for dextroamphetamine.

\section{Off-label prescribing}

Our chart review was not designed to define US Food and Drug Administration (FDA) labeling, nor was it intended to encourage such prescribing habits. Due to this concern we examined the amount of off-label prior drug-use in this population as well as the literature and found a paucity of evidence for most off-label prescribing. When having to decide on changing or adding a medication, factoring in polypharmacy risks and benefits unfortunately is done with inadequate information. The large degree of off-label prescribing should be done with as much data as is available to the prescriber in order to optimize safety and outcome. This secondary analysis was performed to help address this possible criticism of off-label prescribing since it is done with such frequency and insufficient evidence. PEER has the potential to enhance the information available to the prescriber when making these difficult decisions, thus offering some objectivity to off-label usage.

Radley et a ${ }^{41}$ wrote about off-label medication-prescribing, placing psychiatric medications as one of the most frequently prescribed at $31 \%$. Yury et a ${ }^{142}$ found that there is no published data for $40 \%$ of the most popular augmentation strategies and $55 \%$ of frequent combination of medications for augmentation. Additionally, an Agency for Healthcare Research and Quality (AHRQ) report ${ }^{43}$ reviewing the top off-label use of medications according to such factors as risk, cost, side effects, and drug interactions, revealed 17 of them to be psychotropic. Of those studied, $65 \%$ had inadequate evidence for off-label prescribing (ie, quetapine, clonazepam, escitalopram, lorazepam, trazodone, zolpidem, sertraline, bupropion, venlafaxine, duloxetine, aripiprazole). The 
remaining 35\% (ie, gabapentin, risperidone, amitriptyline, olanzapine, devalproex, lamotrigine) averaged $12.5 \%$ adequate evidence, $33.2 \%$ uncertain evidence, and $54.3 \%$ inadequate evidence. In another AHRQ report on off-label use of atypical antipsychotic medications, it concluded that, with few exceptions, there was not enough evidence to consider the off-label use of these drugs and that the increased risk of adverse events was concerning. ${ }^{44}$

We used our own data to perform a review of all the drugs' labeling and dates of approval, using the FDA's website for each medication and approval date for each diagnosis. The date used for the prescribing date of previous medications was "prior to 2003," the beginning date of the review, since patient history of medications start/stop dates is frequently unreliable. This analysis revealed that $62 \%$ of previously prescribed psychotropic medications were offlabel at the time of their prescription date. The number of patients receiving prior off-label medications was $85 \%$. This assessment leaves many variables not accounted for, such as what previous diagnosis the patient had received at the time the drug was prescribed, which might be different than the diagnosis determined in our clinic or what the patient reported. Nevertheless, the finding is worth mentioning. We are not implying any relationship between off-label prescribing and the medications used by PEER guidance. Rather, since there is an abundance of off-label psychotropic medication-prescribing, such prescribing, with more evidenced-based information, can decrease risks and increase success, according to the results of this review.

\section{Study limitations}

Despite the evidence of increased safety and efficacy in this and previous studies, ${ }^{21-30}$ there are several limitations inherent in this retrospective chart review that may limit the conclusions one can draw from a case series. First, the PEER Report was initially established as a predictor of future treatment success. At this point we are not able to separate the role of PEER in selecting the most efficacious treatments from the selection of better-tolerated treatments (since, many times, poorly tolerated treatments are abandoned in clinical practice and ultimately not efficacious). However, it is comforting to see that PEER Reports appear to be associated with effective and well-tolerated medication choices. Second, while this review did not systematically benefit from research-ready data, our analyses suggest overall improvement on both CGI-I and Q-LES-Q-SF global scales after PEER. Third, there was no comparison group in this study so it is not clear what the effects of treatment would have been in a parallel cohort of subjects not utilizing the PEER analysis. However, some information is provided by comparing our results with the patients' pre-PEER experience (ie, treatment failure) and historic data, making each patient's pre/post results their own control. Fourth, this is a cohort of persons who could afford the costs (despite the compassionate sliding scale offered) associated with the EEG test, and thus these patients may not be representative of all similar patients. Fifth, not all available medications are in the current version of the database, leading to potential limitations. However, this would reduce our ability to detect a benefit with PEER Reports compared to standard practice (and increases our confidence in our positive results).

\section{Conclusion}

Our retrospective chart analysis of clinical cases indicates that PEER Report using the referenced-EEG database may be a useful metric tool for clinicians making medication recommendations for refractory nonpsychotic patients. As this data indicates, PEER Report may be useful as a negative marker to potentially avoid some risk of severe adverse events and in selecting more efficacious agents in treatmentresistant patients.

The results of this review are encouraging and indicate that treating patients with the additional information conveyed by the referenced-EEG database and PEER Report may result in better treatment responses in a group of patients who had not previously responded to trial-and-error medication selection (currently considered standard practice).

Some medication recommendations seemed counterintuitive. For example, the use of stimulants in some patients with obsessive-compulsive disorder, anxiety, or eating disorders without the use of an antidepressant would not be a traditional medication choice, yet in these cases appeared to be what was needed for their particular neurophysiology (given positive clinical outcomes).

The potential cost savings as a result of an effective medication regimen suggest that PEER analysis may be cost-effective. The durability of response with medications selected according to data provided by this tool and the broader options of medication combinations suggested by data in the report portends well for treatment compliance, number of medication trials, and treatment efficiency. Getting a patient on the correct medicine with improvement within a few sessions not only reduces the cost of trial-and-error prescribing, but, more importantly, reduces patient suffering. It is also noted that at this point in the 
development of the database, almost all the medications are generic. Similarly, the use of atypical antipsychotics for the nonpsychotic patient in our clinic is estimated to be significantly lower than the use in practices treating similar patient populations.

Future directions for the use of this technology include development of additional drugs and including comparisons with other neuroimaging techniques to address neuroanatomy in addition to clinical correlations. More studies need to be done on the ability to prevent serious adverse events, suicidality, as well as targeting the best medication option for the individualized patient. Finally, a separate database is being completed for predicting outcomes of Transcranial Magnetic Stimulation therapy as a way of deciding the probability of success when the decision to spend health care dollars needs to be considered. Further research in these areas need to confirm the value of QEEG as a simple, inexpensive, and noninvasive outpatient clinical tool for accuracy, safety, and cost savings.

\section{Acknowledgments}

We wish to thank Brian MacDonald, MBA, Deb Arrera, RXN, PMHCNS-BC, and Nicole Shadid, MD, for their tireless and essential assistance in this research.

\section{Disclosure}

DAH is an employee of Neuro-Therapy Clinic, a wholly owned subsidiary of CNS Response Inc, and holds stock in the company. He has also received speaking honoraria from Wyeth, Forest Laboratories, Cephalon, Eli Lilly, Pfizer, and GlaxoSmithKline, but not within the last 5 years.

$\mathrm{CD}$ has received research support in the last 5 years from GSK, Wyeth, Eli Lilly, Cephalon, Cyberonics, Neuronetics, Novaritis, AstraZeneca, Forest, CNS Response, Medtronics, Boerhinger, ANS, Pizer, Neuropace, and Brain Resources. $\mathrm{CD}$ has also received support as a speaker/consultant in the last 5 years from Eli Lilly, GSK, Pizer, Cephalon, Wyeth, BMS, AstraZeneca, Cyberonics, Corcept, Forest. CD is a stock holder in Corcept Therapeutics.

In the past 5 years, RV reports receiving investigatorinitiated funding from Eli Lilly and Company, Forest Research Institute, and H Lundbeck A/S for studies of antidepressant utilization patterns. He has also received funding from the Agency for Healthcare Research and Quality and the American Foundation for Suicide Prevention.

DI, in the last 2 years, has been a consultant for CNS Response, Inc. Over his lifetime, DI has received research support from Aspect Medical Systems, Forest Laboratories, and Janssen Pharmaceutical. He has been a consultant for Forest Laboratories, Gerson Lehrman Group, and Pfizer, Inc, and he has been a speaker for Eli Lilly and Co, Forest Laboratories, Pfizer, Inc, and Reed-Elsevier.

\section{References}

1. Hoffman DA, Schiller M, Greenblatt JM, Iosifescu DV. Polypharmacy or medication washout: an old tool revisited. Neuropsychiatr Dis Treat. 2011;7(1):639-648.

2. Woods SW, Morgenstern H, Saksa JR, et al. Incidence of tardive dyskinesia with atypical versus conventional antipsychotic medications: a prospective cohort study. J Clin Psychiatry. 2010; 71(4):463-474.

3. Frye MA, Ketter TA, Leverich GS, et al. The increasing use of polypharmacotherapy for refractory mood disorders: 22 years of study. J Clin Psychiatry. 2000;61(1):9-15.

4. Mojtabai R, Olfson J. National trends in psychotropic medication polypharmacy in office-based psychiatry. Arch Gen Psychiatry. 2010;67(1):26-36.

5. Hajjar ER, Cafiero AC, Hanlon JT. Polypharmacy in elderly patients. Am J Geriatr Pharmacother. 2007;5(4):345-351.

6. Gurvich T, Cunningham JA. Appropriate use of psychotropic drugs in nursing homes. Am Fam Physician. 2000;61(5):1437-1446.

7. Feil D, Weinreb J, Sultzer D. Psychiatric disorders and psychotropic medication use in elderly persons with diabetes. Ann Longterm Care. 2006;14(7):39-47.

8. Nicole Damestoy N, Collin J, Lalande R. Prescribing psychotropic medication for elderly patients: some physicians' perspectives. CMAJ. 1999;161(2):143-145.

9. Montamat SC, Cusack B. Overcoming problems with polypharmacy and drug misuse in the elderly. Clin Geriatr Med. 1992;8(1):143-158.

10. Kingsbury L. Psychiatric polypharmacy: the good, the bad, and the ugly. Psychiatr Times. 2007;24(4):1-3.

11. Helwick C. Polypharmacy is common in psychiatry, but is more better? Medscape Medical News . September 7, 2010. Available from: http:// www.medscape.com/viewarticle/728132. Accessed October 3, 2011.

12. Dao J, Carey B, Frosh D. For some troops, powerful drug cocktails have deadly results. New York Times. February 12, 2011. Available from: http://www.nytimes.com/2011/02/13/us/13drugs. html?ref=benedictcarey. Accessed September 16, 2011.

13. Mojtabai R, Olfson M. National patterns in antidepressant treatment by psychiatrists and general medical providers: results from the national comorbidity survey replication. $J$ Clin Psychiatry. 2008;69(7):1064-1074.

14. http://www.nimh.nih.gov [homepage on the Internet]. Maryland: National Institute of Mental Health [updated December 14, 2010; cited August 30, 2010]. Available from http://www.nimh.nih.gov/about/ director/2010/taking-clinical-research-to-the-next-level.shtml?WT. mc_id=rss. Accessed December 22, 2011.

15. Insel T, Cuthbert B, Garvery M, et al. Research domain criteria (RDoC): toward a new classification framework for research on mental disorders. Am J Psychiatry. Jul 2010;167(7):748-751.

16. Insel TR. Disruptive insights in psychiatry: transforming a clinical discipline. J Clin Invest. 2008;119(4):700-705.

17. Greenberg G. Inside the battle to define mental illness. Wired. December 27, 2010. Available from: http://www.wired.com/ magazine/2010/12/ff dsmv/all/1. Accessed January 20, 2011.

18. Rush AJ, Fava M, Wisniewski SR, et al; STAR*D Investigators Group. Sequenced treatment alternatives to relieve depression (STAR*D): rationale and design. Control Clin Trials. 2004;25(1):119-142.

19. Fava M, Rush AJ, Alpert JE, et al. Difference in treatment outcome in outpatients with anxious versus nonanxious depression: a STAR*D report. Am J Psychiatry. 2008;165(3):342-351.

20. Rush AJ. The varied clinical presentations of major depressive disorder. J Clin Psychiatry. 2007;68 Suppl 8:4-10. 
21. Hunter AM, Leuchter AF, Morgan ML, et al. Neurophysiologic correlates of side effects in normal subjects randomized to venlafaxine or placebo. Neuropsychophar. 2005;30:792-799.

22. Iosifescu DV, Greenwald S, Devlin P, et al. Pretreatment frontal EEG and changes in suicidal ideation during SSRI treatment in major depressive disorder. Acta Psych Scan. 2008;117:271-276.

23. Suffin SC, Emory WH. Neurometric subgroups in attentional and affective disorders and their association with pharmacotherapeutic outcome. Clin EEG Neurosci. 1995;26:76-83.

24. Schiller MJ, Emory WH, Shaffer J, et al. EEG guidance of psychopharmacologic treatment: multi-site experience [Poster 10]. Proceedings of the 158th Annual Meeting of American Psychiatric Association; May 21-26, 2005; Atlanta, GA.

25. Shaffer JH, Milner JE, Schiller MJ. rEEG-Guided Pharmacotherapy for Severely Ill, Dually Diagnosed Patients [Poster 684]. Proceedings of the 158th Annual Meeting of American Psychiatric Association; May 21-26, 2005; Atlanta, GA.

26. Suffin SC, Emory WH, Gutierrez N, et al. A QEEG method for predicting pharmacotherapeutic outcome in refractory major depressive disorder. J Am Phys Surg. 2007;12(4):104-108.

27. Schiller M, Emory WH, Suffin SC. Referenced-EEG in the treatment of eating disorders [Poster 221]. Proceedings of the 44th Annual National Institute of Mental Health (NIMH) New Clinical Drug Evaluation Meeting (NCDEU); June 1-4, 2004; Phoenix, AZ.

28. DeBattista C, Hoffman D, Schiller M, Iosifescu D. Referenced-EEG (rEEG) guidance of medications for treatment resistant depressed patients - a pilot study [Poster 228]. Proceedings of the 21st Annual US Psychiatric and Mental Health Congress; October 30-November 2, 2008; San Diego, CA.

29. Debattista C, Kinrys G, Hoffman D, et al. The use of referenced EEG $(\mathrm{rEEG})$ in assisting medication selection for the treatment of depression. J Psychiatr Res. 2011;45(1):64-75.

30. Greenblatt JM, Sussman C, Jameson M, Yuan L, Hoffman DA, Iosifescu DV. Retrospective chart review of a referenced EEG database in assisting medication selection for treatment of depression in patients with eating disorders. Neuropsychiatr Dis Treat. 2011;7(1): 529-541.

31. Guy W. ECDEU Assessment Manual for Psychopharmacology-Revised (DHEW Publ No ADM 76-338). Rockville, MD: US Department of Health, Education, and Welfare; Public Health Service; Alcohol, Drug Abuse, and Mental Health Administration; NIMH Psychopharmacology Research Branch; Division of Extramural Research Programs; 1976:218-222.

32. Guy W. Clinical Global Impressions (CGI) Scale. Modified from: Rush J, et al. Psychiatric Measures. Washington, DC: APA; 2000.
33. Endicott J, Nee J, Harrison W, Blumenthal R. Quality of life enjoyment and statistical questionnaire: a new measure. Psychopharacol Bull. 1993;29(2):321-326.

34. Schechter D, Endicott J, Nee J. Quality of life of normal controls: association with lifetime history of mental illness. Psychiatry Res. 2007;152(1):45-54. doi: 10.1016/j.psychres.2006.09.008.

35. Chand PK, Mattoo SK, Sharan P. Quality of life and its correlates in patients with bipolar disorder stabilized on lithium prophylaxis. Psychiatry Clin Neurosci. 2004;58(3):311-318.

36. Kocsis JH, Zisook S, Davidson J, et al. Double-blind comparison of sertraline, imipramine, and placebo in the treatment of dysthymia: psychosocial outcomes. Am J Psychiatry. 1997;154(3):390-395.

37. Pollack MH, Otto MW, Worthington JJ, Manfro GG, Wolkow R. Sertraline in the treatment of panic disorder: a flexible-dose multicenter trial. Arch Gen Psychiatry. 1998;55(11):1010-1016.

38. Liebowitz MR, DeMartinis NA, Weihs K, et al. Efficacy of sertraline in severe generalized social anxiety disorder: results of a double-blind, placebo-controlled study. J Clin Psychiatry. 2003;64(7):785-792.

39. Zisook S, Trivedi MH, Warden D, et al. Clinical correlates of the worsening or emergence of suicidal ideation during SSRI treatment of depression: an examination of citalopram in the STAR*D study. J Affect Disord. Sep 2009;117(1-2):63-73.

40. Warden D, Rush AJ, Wisniewski SR, et al. What predicts attrition in second step medication treatments for depression?: a STAR*D Report. Int J Neuropsychopharmacol. 2009;12(4):459-473.

41. Radley DC, Finkelstien SN, Stafford RS. Off-label prescribing among office-based physicians. Arch Intern Med. 2006;166:1021-1026.

42. Yury C, Fisher J, Valenstein M, Matuszak J. Meta-analysis of antidepressant augmentation piling on in the absence of evidence. Ethical Hum Psychol and Psychiatry. 2009;11(3).

43. Walton SM, Schumock GT, Lee K-V, et al. Developing evidence-based research priorities for off-label drug use. Effective Health Care Research Report 12. (Prepared by the University of Illinois at Chicago DEcIDE Center Under Contract No HHSA29020050038I T03.) Rockville, MD: Agency for Healthcare Research and Quality; 2009.

44. Maglione M, Ruelaz, Maher A, Hu J, et al. Off-Label Use of Atypical Antipsychotics: An Update. Comparative Effectiveness Review No. 43. (Prepared by the Southern California/RAND Evidence-based Practice Center under Contract No. HH54290-2007-10062-1.) AHRQ Publication No. 11-EHC087-EF. Rockville, MD; Agency for Healthcare Research and Quality. September 2011. Available from: www. effectivehealthcare.ahrq.gov/reports/finalcfm. Accessed January 20, 2011.
Neuropsychiatric Disease and Treatment

\section{Publish your work in this journal}

Neuropsychiatric Disease and Treatment is an international, peerreviewed journal of clinical therapeutics and pharmacology focusing on concise rapid reporting of clinical or pre-clinical studies on a range of neuropsychiatric and neurological disorders. This journal is indexed on PubMed Central, the 'PsycINFO' database and CAS.

\section{Dovepress}

The manuscript management system is completely online and includes a very quick and fair peer-review system, which is all easy to use. Visit http://www.dovepress.com/testimonials.php to read real quotes from published authors. 